\title{
Kontroler Proporsional Integral Motor Servo untuk Kesalahan Kontur
}

\author{
${ }^{1}$ Abdul Hadi dan ${ }^{2}$ Zainal Abidin \\ 1,2 Jurusan Teknik Elektro, Politeknik Negeri Bengkalis \\ Jl. Bathin Alam, Sungai Alam, Bengkalis \\ e-mail: abdulhadi@polbeng.ac.id
}

\begin{abstract}
Abstrak --- Penerapan metode kontroler konvensional seperti kontroler Proporsional Modifikasi menghasilkan error yang masih cukup besar. Hal ini akan mempengaruhi akurasi dan presisi dari hasil produk saat motor servo diterapkan pada kontrol posisi. Penelitian ini mengajukan sistem kontrol Proporsional Integral pada motor servo untuk mengurangi kesalahan pada waktu setelah rise time. Selain itu, besaran kesalahan juga diukur pada kontur linear dan nonlinear menggunakan RMSE sejak waktu nol detik. Dari hasil eksperimen menggunakan tiga sinyal uji diatas, dapat disimpulkan bahwa kontroler proporsional integral mampu mempercepat respon terbukti dengan nilai delay time sebesar 0,15 detik. Untuk error steady state menuju ke nol dimulai waktu 60 detik. Selanjutnya untuk kontroler proporsional integral pada motor servo, kontrol posisi dikontur linear menghasilkan nilai RMSE 10,0101 dan dikontur nonlinear memiliki RMSE yaitu 2,5192. RMSE pada kontur nonlinear lebih kecil dibandingkan dengan kontur linear.
\end{abstract}

Kata Kunci: Kontrol Proporsional Integral, RMSE, Error Steady State, Kesalahan Kontur

\begin{abstract}
The application of conventional controller methods such as the Modified Proportional controller results in quite a large error. This will affect the accuracy and precision of the product output when the servo motor is applied to position control. This research proposes an Integral Proportional control system in servo motors to reduce the error in the time after the rise time. In addition, the magnitude of the error is also measured on linear and nonlinear contours using RMSE since time zero seconds. From the experimental results using the three test signals above, it can be concluded that the integral proportional controller is able to accelerate the response as proven by a delay time value of 0.15 seconds. For steady state error goes to zero, it starts at 60 seconds. Furthermore, for the integral proportional controller on the servo motor, the linear contour position control produces an RMSE value of 10.0101 and the nonlinear contour has an RMSE of 2.5192. RMSE on nonlinear contours is smaller than on linear contours.
\end{abstract}

\section{Keyword : Proportional Integral Control, RMSE, Error Steady State, Contour Error}

\section{PENDAHULUAN}

Penerapan metode kontroler konvensional seperti kontroler Proporsional pada sistem motor servo didasarkan pada banyaknya kontrol cerdas namun masih belum mampu dalam skala implementasi terkait dengan keterbatasan sistem [1]. Sistem kontrol cerdas seperti neural network ataupun kombinasinya masih belum mengarah kepada implementasi sistem riil [2][3]. Metode kontroler proporsional modifikasi masih menghasilkan error yang tidak nol ketika diberi sinyal uji step. Hal ini mengurangi performansi sistem kontrol yang diterapkan [7].

Penelitian ini mengajukan metode kontroler proporsional integral pada motor servo, dimana pada penelitian sebelumnya masih terdapat kekurangan terkait error yang dikontrol tidak benar-benar menuju nilai nol [7]. Hal ini dikarenakan kinerja Kontroler Proporsional Modifikasi belum mampu untuk mengontrol secara akurat. Padahal, untuk kontrol posisi pada motor servo membutuhkan tingkat akurasi dan presisi yang tinggi. Jika kurang akurasi dan presisi maka akan menghasilkan produk yang berkualitas rendah.

Penelitian ini mengajukan metode kontroler Proporsional Integral pada Motor Servo untuk meningkatkan akurasi dan presisi motor servo saat dikontrol posisi. Besar akurasi dan presisi dibuktikan dengan parameter Root Mean Square Error (RMSE) saat mencapai rise time pada saat sinyal uji step dan pada sinyal uji ramp dan sinusoidal dimulai dari waktu nol detik [5]. Nilai gain pada Kontroler PI ini akan dicari menggunakan analisa gain karena bertujuan meningkatkan keilmiahan dari pencarian gain [4].

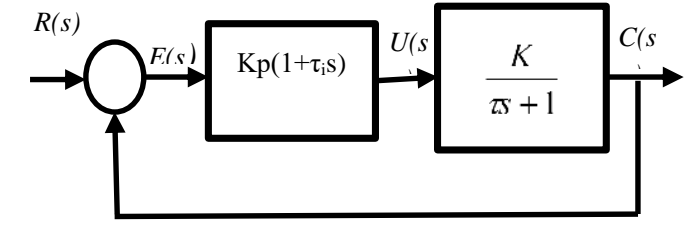

Gambar 1. Diagram Blok Sistem Kontroler Proporsional Integral 
Gambar 1 diatas menggambarkan diagram blok sistem kontrol proporsional integral pada sistem orde satu. $R(s)$ merupakan referensi, $E(s)$ merupakan error keluaran sistem yang dideteksi. Keluaran kontroler berupa $U(s)$ dan keluaran sistem yang dikontrol yaitu $C(s)$. Untuk $K p$ merupakan gain kontroler proporsional dan $\tau_{i}$ merupakan gain kontroler integral.

\section{METODE KONTROLER PROPORSIONAL INTEGRAL}

Dari Gambar 1 diatas menggambarkan diagram blok sistem kontrol proporsional integral dengan mengontrol plant orde satu. Pada kontroler proporsional integral terdapat dua gain atau parameter kontroler yaitu $K p$ dan $\tau_{i}$. Jika kontroler Proporsional ditambah Integral diterapkan pada plant orde pertama maka fungsi alih dari diagram blok tersebut diperoleh pada Persamaan (1).

$$
\frac{C(s)}{R(s)}=\frac{K p\left(\frac{\tau_{i} s+1}{\tau_{i} s}\right)\left(\frac{K}{\tau s+1}\right)}{1+K p\left(\frac{\tau_{i} s+1}{\tau_{i} s}\right)\left(\frac{K}{\tau s+1}\right)}
$$

Dari Persamaan (1) diperoleh seperti Persamaan (2) dan (3) yaitu dengan diasumsikan $\tau_{i}=\tau$ maka.

$$
\begin{aligned}
& \frac{C(s)}{R(s)}=\frac{\frac{K p \cdot K}{\tau_{i} s}}{1+\frac{K p \cdot K}{\tau_{i} s}} \\
& \frac{C(s)}{R(s)}=\frac{1}{\frac{\tau_{i} s}{K \cdot K p}+1}
\end{aligned}
$$

Tampak dari Persamaan (3) suatu plant orde satu dengan kontroler Proporsional ditambah Integral menghasilkan sistem orde pertama atau model yang diinginkan adalah sistem orde pertama dengan asumsi $\tau_{i}=\tau$ dengan fungsi alih seperti Persamaan (4) berikut.

$$
\frac{C(s)}{R(s)}=\frac{K^{*}}{\tau^{*} \mathrm{~s}+1}
$$

Dibandingkan Persamaan (3) dan (4) diatas diperoleh Persamaan (5) dan (6).

$$
\begin{gathered}
\tau^{*}=\frac{\tau_{i}}{K \cdot K p} \\
K^{*}=1
\end{gathered}
$$

Untuk masukan unit step, nilai error steady state dapat dihitung dengan Persamaan (7) berikut.

$$
e_{s s}=R(s)-C(s)
$$

Dimana C(s) adalah Keluaran dan R(s) adalah Masukan, maka nilai error diperoleh dari hubungan terhadap waktu dari masing-masing Persamaan (8) dan (9) dimana menghasilkan Persamaan (10) berikut.

$$
\begin{gathered}
R(s)=\lim _{s \rightarrow 0} s R(s)=\lim _{s \rightarrow 0} s\left(\frac{1}{s}\right)=1 \\
C(s)=\lim _{s \rightarrow 0} s C(s)=\lim _{s \rightarrow 0} s\left(\frac{1}{s\left(\tau^{*} s+1\right)}\right)=1 \\
e_{s s}=R(s)-C(s)=1-1=0
\end{gathered}
$$

Dari Persamaan (10) dapat diperoleh bahwa plant sistem orde pertama yang dikontrol dengan metode kontrol Proporsional Integral menghasilkan error steady state bernilai nol. Untuk menghasilkan gain kontroler proporsional $(K p)$ dan gain Integral $\tau_{i}$, dimana diperoleh dari Persamaan (5) dengan asumsi $\tau_{i}=\tau$ maka diperoleh Persamaan (11) dan (12) berikut.

$$
\begin{gathered}
\tau_{i}=\tau \\
K p=\frac{\tau_{i}}{K \cdot \tau^{*}}
\end{gathered}
$$

Jadi, gain kontroler integral $\left(\tau_{i}\right)$ diperoleh dari Persamaan (11), sedangkan gain kontroler proporsional $(\mathrm{Kp})$ diperoleh dari Persamaan (12).

\section{ANALISA METODE KONTROLER PROPORSIONAL INTEGRAL}

Penerapan kontroler Proporsional Integral digunakan untuk mengontrol motor servo dengan menggunakan fungsi alih dari penelitian (Erista, 2012) [6]. Bentuk sistem kontrol Proporsional Integral untuk fungsi alih yang dikontrol dapat dilihat pada Gambar 2.

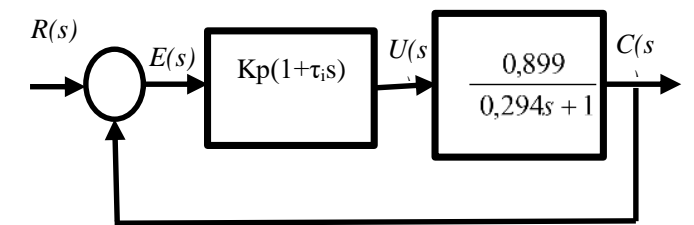

Gambar 2. Sistem Kontrol Proporsional Integral pada Motor Servo

Dari Gambar 2 diatas, $K p$ merupakan gain kontroler proporsional dan $\tau$ i merupakan gain kontroler integral. Eksperiment dilakukan dengan mendesain gain kontroler proporsional $(K p)$ dan gain integral $\left(\tau_{i}\right)$ yang berhubungan dengan fungsi alih plant yang dikontrol. Dari Gambar (2) pada bagian plant digambarkan pada Persamaan (13) dimana diperoleh Persamaan (14) dan (15). 


$$
\begin{gathered}
G(s)=\frac{0,899}{0,294 s+1} \\
K=0,899 \\
\tau=0,294
\end{gathered}
$$

Desain kontroler proporsional integral ini berhubungan dengan time constant respon keluaran yang diinginkan. Pada desain ini diinginkan time constant hasil desain $\left(\tau^{*}\right)$ tiga kali lebih cepat dari time constant $(\tau)$ semula, sehingga berlakulah Persamaan (16) dan diperoleh Persamaan (17).

$$
\begin{gathered}
3 \tau^{*}=\tau \\
\tau^{*}=\frac{0,294}{3} \text { detik }
\end{gathered}
$$

Dengan diinginkan hasil desain memiliki time constant respon keluaran tiga kali lebih cepat dari time constant semula diperoleh seperti Persamaan (17).

Setelah diperoleh $\tau^{*}$ seperti pada Persamaan (17), maka diperoleh Gain Kontroler Proporsional ( $K p)$ dan Gain Integral $\left(\tau_{i}\right)$ menggunakan Persamaan (11) dan (12), seperti hasil pada Persamaan (18) dan (19).

$$
\begin{gathered}
K p=\frac{0,882}{0,264304} \\
\tau_{i}=0,294
\end{gathered}
$$

Dari hasil desain diatas diperoleh $K p$ dan $\tau_{i}$, dimana hasil ini akan dibuktikan dengan berdasarkan simulasi Simulink.

Sinyal uji dari desain kontroler yang saya terapkan diuji dengan menggunakan 3 sinyal uji yaitu step, ramp dan sinusoidal. Sinyal step dengan final value atau setpoint 100 , sinyal ramp dengan slope sebesar 2 dan nilai sinusoidal dengan frekuensi 6,28 rad/s atau sama dengan $1 \mathrm{~Hz}$ dan amplitudo sebesar $1 \mathrm{~cm}$. Untuk sinyal uji step digunakan untuk menilai delay time dan rise time sedangkan untuk sinyal uji ramp dan sinusoidal digunakan untuk menguji pengaruh plant ketika dikontrol posisi untuk kontur linear dan nonlinear. Sinyal ramp digunakan untuk kontur linear sedangkan sinyal Sinusoidal untuk sinyal nonlinear. Hasil dari simulasi untuk kontur linear dan nonlinear akan dilihat besarnya kesalahan berdasarkan Root Mean Square Error (RMSE) dari Persamaan (20) berikut.

$$
R M S E=\sqrt{\sum_{i=1}^{N}(E)^{2}}
$$

\section{HASIL DAN PEMBAHASAN}

Simulasi pengujian akan dilakukan dengan tiga jenis sinyal uji yaitu fungsi step, ramp dan sinusoidal. Sinyal uji fungsi step digunakan untuk membuktikan ketercapaian delay time dan rise time dari desain yang dihasilkan. Sinyal uji fungsi Ramp ini bertujuan untuk membuktikan ketercapaian saat motor servo dikontrol posisi untuk kontur linear. Untuk sinyal uji sinusoidal digunakan untuk membuktikan ketercapaian saat motor servo dikontrol posisi untuk kontur nonlinear. Untuk parameter Kontroler Proporsional dan Integral akan dimasukkan nilai $K p=\frac{0,882}{0,264304}$ dan $\tau_{i}=0,294$ seperti pada Persamaan (18) dan (19).

Pada sinyal uji step ini akan diberikan parameter berupa setpoint sebesar 100 dimana step time dari nol dengan durasi simulasi 100 detik sehingga diperoleh seperti pada Gambar (3) berikut ini.

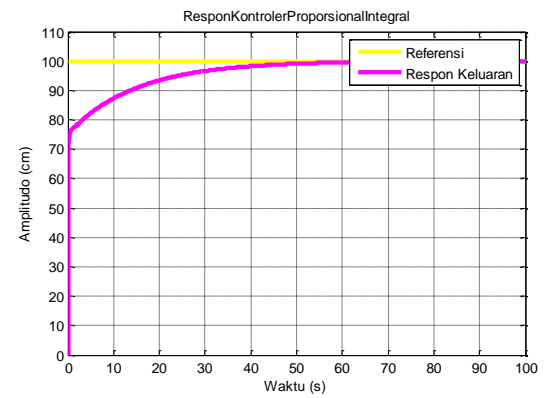

Gambar 3 : Respon Referensi dan Keluaran dengan Sinyal Uji Step

Dari Gambar (3) diatas diperoleh delay time pada 0,15 detik dan rise time pada 60 detik. Dari hasil eksperimen ini membuktikan kontroler proporsional integral mampu mempercepat respon tiga kali lebih cepat dari time constant semula yaitu 0,294 detik. Untuk error steady state kesalahan dapat menuju nol dimulai dari detik 60 tersebut.

Sinyal uji kedua yaitu sinyal Ramp dimana digunakan untuk menguji sistem motor servo ketika diberi setpoint linear. Sinyal uji step ini dimasukkan dengan kemiringan (slope) sebesar 2 dengan durasi simulasi 6 detik sehingga diperoleh Gambar 4 berikut ini.

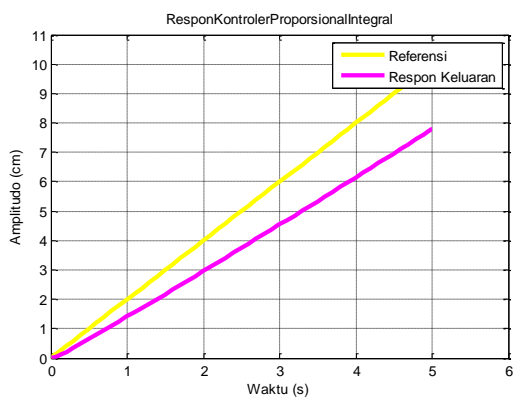

Gambar 4 : Respon Referensi dan Keluaran dengan Sinyal Uji Ramp

Dari Gambar (4) diatas membuktikan posisi motor servo yang dikontrol dengan metode kontroler proporsional integral menghasilkan keluaran dengan nilai RMSE yaitu 10,0101.

Sinyal uji ketiga yaitu sinyal sinusoidal dimana digunakan untuk menguji sistem motor servo ketika diberi setpoint nonlinear. Sinyal sinusoidal ini dimasukkan dengan besar 
amplitudo $1 \mathrm{~cm}$ dan frekuensi 6,28 rad/s atau sama dengan 1 Hertz dengan durasi simulasi 4 detik, sehingga dapat dilihat hasil simulasi seperti Gambar 5 berikut ini.

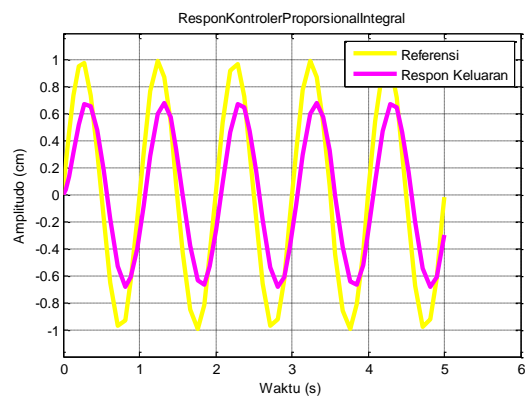

Gambar 5 : Respon Referensi dan Keluaran dengan Sinyal Uji Sinusoidal

Berdasarkan Gambar (5) diatas membuktikan posisi motor servo yang dikontrol dengan metode kontroler proporsional integral menghasilkan nilai RMSE yaitu 2.5192.

\section{KESIMPULAN}

Dari hasil eksperimen menggunakan tiga sinyal uji diatas, dapat disimpulkan bahwa kontroler proporsional integral sudah mampu mempercepat respon terbukti dengan nilai delay time lebih 3 kali lebih kecil dari konstanta waktu semula.
Untuk error steady state menuju ke nol dimulai waktu 60 detik. Selanjutnya untuk kontroler proporsional integral pada motor servo, pada kontrol posisi dikontur linear menghasilkan nilai RMSE 10,0101 dan dikontur nonlinear memiliki RMSE yaitu 2,5192. RMSE pada kontur nonlinear lebih kecil dibandingkan dengan kontur linear.

\section{REFERENSI}

[1] A. Hadi, Kontrol Proporsional untuk Motor Servo, Prosiding Seminar Nasional Industri dan Teknologi (SNIT), Politeknik Negeri Bengkalis, Bengkalis 2016.

[2] C. K. Lee, T. H. M. Chow, dan D. K. W. Cheng, DC Servo Motor Controllers Based on a Neural Network, Hong Kong Polytechnic, Hong Kong, 287-292.

[3] E. A. Ebrahim, A Novel Approach of an Adaptive Neuro-PI Vector Controller Fed Induction Motor Servo, Proceedings of the IEEE/RSJ of International Conference on Intelligent Robots and Systems, Switzerland, 2002.

[4] A, Hadi, Perbandingan Tuning Parameter Kontroler PD menggunakan Metode Trial And Error dengan Analisa Gain pada Motor Servo AC, Jurnal Inovasi dan Teknologi (Inovtek) Vol 6 No. 1, 2016.

[5] Chal, T dan Draxler, R. R., Root mean square error (RMSE) or mean absolute error (MAE) - Arguments against avoiding RMSE in the literature, Published in Geosci. Model Dev. Discuss.:, 2014.

[6] Safitri, E, B, dkk., Implementasi Kontroler P-PI Kaskade untuk Meningkatkan Keakuratan Mesin Bubut CNC . JURNAL TEKNIK ITS Vol 1. F75-F80, 2012.

[7] A. Hadi, Kontroler Proporsional Modifikasi pada Motor Servo, Jurnal PROtek Vol 6 No 2 Tahun 2019, Halaman 59 - 62. 